\title{
Privacidade em unidades de terapia intensiva: direitos do paciente e implicações para a enfermagem
}

\author{
Privacy in critical care units: the patient's rights and implications for nursing professionals
}

Privacidad en unidades de cuidados intensivos: derechos del paciente y implicaciones para los profesionales de enfermería

\author{
Maria Aparecida Baggio', Dalva Maria Pomatti", Luiz Antonio Bettinelli', AlacoQue Lorenzini Erdmann' \\ 'Universidade Federal de Santa Catarina. Programa de Pós-graduação em Enfermagem. Florianópolis, SC \\ "Universidade de Passo Fundo. Programa de Mestrado em Envelhecimento Humano. Passo Fundo, RS
}

Submissão: 14/09/2009

Aprovação: 12/09/2010

\section{RESUMO}

O objetivo deste estudo foi compreender as experiências vivenciadas pelos profissionais da enfermagem sobre a privacidade do paciente internado em UTI e suas implicações. Este estudo Qualitativo, mediante análise de conteúdo, originou as categorias: Expondo o corpo e a intimidade dos pacientes: atitudes e ações dos profissionais; A intimidade: dificuldades vividas pelos profissionais e reações dos pacientes; Desproteção da intimidade do paciente: contradições Que emergem da prática. Os resultados apontam a necessidade dos profissionais repensarem o seu fazer em relação à proteção da privacidade do paciente, por meio de atos/atitudes Que transmitam segurança nas ações do cuidado. A preservação da privacidade é direito do paciente e compromisso ético do profissional, conferindo dignidade às pessoas no processo de cuidado na UTI.

Descritores: Enfermagem; Ética de enfermagem; Unidades de terapia intensiva.

\section{ABSTRACT}

The purpose of this study was to understand the experiences of nursing professionals about the patient's privacy hospitalized in the ICU and their implications. This Qualitative study based on content analysis revealed the following categories: Exposing the patients' body and intimacy: the professionals' attitudes and actions; intimacy: difficulties experienced by the professionals and the patients' reactions; the lack of intimacy protection of the patient: contradictions that arise from the practice. The results point to the need for professionals to rethink their achievements in relation to the protection of the patient's privacy, by means of acts/attitudes which provide security in care actions. Privacy preservation is the patient's right and the professional's ethical commitment, giving to people dignity in the care process in the ICU.

Key words: Nursing; Nursing ethics; Intensive Care Unit.

\section{RESUMEN}

El objetivo de este estudio fue comprender las experiencias vividas por los profesionales de enfermería respecto a la privacidad del paciente internado en UCl y sus implicaciones. Este estudio cualitativo, mediante análisis de contenido, originó las categorías: Exponiendo el cuerpo y la intimidad de los pacientes: actitudes y acciones de los profesionales; La intimidad: dificultades vividas por los profesionales y reacciones de los pacientes; Desprotección de la intimidad del paciente: contradicciones Que emergen de la práctica. Los resultados apuntan la necesidad de los profesionales repensaren su hacer en relación a la protección de la privacidad del paciente, por medio de actos/actitudes Que transmitan seguridad en las acciones del cuidado. La preservación de la privacidad es un derecho del paciente y un compromiso ético del profesional, confiriendo dignidad a las personas en el proceso de cuidado en la $\mathrm{UCI}$.

Descriptores: Enfermería; Ética de enfermería; Unidades de cuidados intensivos.

AUTOR Maria Aparecida Baggio. Campus Universitário Reitor João David Ferreira Lima. Trindade. CEP 88040-970.

CORRESPONDENTEＦlorianópolis, SC.E-mail: mariabaggio@yahoo.com.br 


\section{INTRODUÇÃO}

A internação de um paciente em unidade de tratamento intensivo (UTI) é precedida de condições críticas, presentes e potenciais, Que colocam em risco a vida do ser. Por isso, o cuidado é voltado para os aspectos físicos/orgânicos/biológicos, como controle e manutenção das funções vitais, com ênfase no uso de tecnologias e aplicação de conhecimento técnico-científico, visando à manutenção da vida. Embora a equipe de saúde tenha sua atenção voltada ao órgão doente, à patologia ou busca de diagnóstico Que orientam suas condutas e procedimentos técnicos, muitas vezes ignora os sentimentos dos seres Que vivenciam a internação e a condição de doentes ${ }^{(1)}$.

A experiência da internação em ambiente de cuidados intensivos, em razão das suas características e rotinas, muitas vezes rígidas e inflexíveis, pode gerar ao paciente desconforto, impessoalidade, dependência da tecnologia, isolamento social, falta de privacidade, perda de identidade, autonomia, dentre outros, rompendo bruscamente com seu modo de viver, Que inclui suas relações e seus papéis. Neste caso, a identidade e autonomia são afetadas, em virtude de o paciente ser considerado incapaz de escolher, decidir, opinar e expressar-se. Assim, o princípio da autonomia não é exercido nem mesmo nas situações de higiene pessoal, alimentação, eliminações, etc, configurando sujeição parcial ou total dos que o cuidam, como um mero receptáculo de cuidados técnicos e intensivos ${ }^{(1)}$.

Conforme os princípios da bioética, o respeito à autonomia implica respeitar os atos de escolha do indivíduo, baseados em seus valores morais e crenças, sendo a vontade e o consentimento fatores preponderantes, porque afirmam sua dignidade humana ${ }^{(2)}$.

Diante do exposto, o ambiente de UTI envolve diversos componentes éticos e técnicos Que reQuerem atenção dos envolvidos no processo. Apesar do esforço dos profissionais no sentido de humanizar o cuidado, é esta uma tarefa difícil nesse ambiente, Que requer atitudes individuais e coletivas para que sejam respeitadas a privacidade, a individualidade e a dignidade dos pacientes.

Dessa forma, pacientes conscientes internados no ambiente de UTI, além do sofrimento pelo comprometimento biológico, demonstram desconforto e constrangimento por estarem despidos e serem, muitas vezes, expostos e invadidos em sua intimidade. A perda da privacidade é, portanto, condição adicional de estresse e sofrimento durante a hospitalização( ${ }^{(3)}$.

Na realização do cuidado, o profissional de enfermagem muitas vezes precisa expor o corpo do paciente e ou partes íntimas para a execução de procedimentos, condição Que invariavelmente constrange e embaraça o ser exposto, Que tem invadida a sua privacidade. A condição de ver o corpo despido fere seu pudor, Que é produto de sua cultura.

Embora não seja este um problema recente, os profissionais de enfermagem pouco discutem o tema, o Que constitui uma deficiência nesta dimensão do cuidado ${ }^{(4)}$. Por essa razão, indagamos: Como os profissionais vivenciam a exposição do corpo e intimidade do paciente na realização de procedimentos e cuidados em ambiente de cuidados intensivos? Ocorre invasão da privacidade dos pacientes durante a realização de procedimentos na visão dos profissionais? Que Questões éticas estão implicadas?

Posto isso, este estudo objetivou compreender as experiências vivenciadas pelos profissionais de enfermagem sobre a privacidade do paciente internado em UTI e suas implicações.

\section{METODOLOGIA}

Este estudo, de natureza Qualitativa fundamentado na análise temática. Foi desenvolvido com 22 profissionais de enfermagem Que atuam em unidades de terapia intensiva, há mais de três anos (por permitir maior vivência com as situações investigadas), em dois hospitais de uma cidade do interior do Rio Grande do Sul. O projeto de pesquisa seguiu todas as recomendações da Resolução № 196 do Ministério da Saúde ${ }^{(5)}$, sendo submetido e aprovado pelo Comitê de Ética em Pesquisa da Universidade de Passo Fundo, sob o n ${ }^{\circ} 865 / 2006$.

A coleta de dados foi realizada com entrevista individual, semiestruturada, agendada previamente, concedida pelos participantes mediante assinatura do Termo de Consentimento Livre e Esclarecido. Constituíram o roteiro das entrevistas, as seguintes Questões: Você pede licença ao tocar o paciente? Como você se comporta Quando precisa expor o corpo do paciente para a realização do cuidado? Você tem a preocupação de proteção e de manutenção da privacidade e/ou intimidade do paciente? Os pacientes demonstram algum tipo de reação no cuidado Quando é necessária a exposição corporal? Você tem algum tipo de dificuldade em lidar com situações Que envolvem a exposição corporal e a desproteção da intimidade do paciente? Você tem algum tipo de dificuldade em fazer algum procedimento em Que há a exposição corporal de um paciente do sexo oposto ao seu? Para você, os profissionais de enfermagem Que atuam na unidade de cuidados intensivos se preocupam em proteger a privacidade do paciente? Que preocupações possuem? Relate como acontece o cuidado em Que há necessidade de toque corporal nas partes íntimas e o Que os pacientes manifestam ou mencionam nessas situações? Como você pensa Que deveria ser a abordagem para a proteção e manutenção da privacidade e/ou intimidade do paciente? Os participantes foram identificados pela letra " $p$ ", seguida do número ordinal respectivo à ordem da entrevista (p l , p2 ...), garantindo-se, assim, o seu anonimato.

Os dados foram analisados e interpretados utilizando-se o método de análise temática de conteúdo, Que "consiste em descobrir os núcleos de sentido Que compõem uma comunicação, cuja presença ou fręuência signifieuem alguma coisa para o objetivo analítico visado"(6). Assim, agrupando-se as unidades temáticas, originaram-se as categorias, as Quais foram analisadas à luz da literatura concernente ao tema ${ }^{(7)}$.

\section{RESULTADOS E DISCUSSÃO}

Os participantes do estudo possuem idade entre 2 I e 42 anos, sendo 18 do sexo feminino e Quatro do masculino, com experiência entre três e 19 anos; seis possuem formação de nível superior, Quatro superior incompleto e 12 de nível médio. Do processo de categorização dos discursos dos profissionais emergiram três categorias, com as respectivas subcategorias, apresentadas e analisadas a seguir.

Expondo o corpo e a intimidade dos pacientes: atitudes e 


\section{ações dos profissionais - agindo naturalmente}

A exposição do corpo e da intimidade é uma condição única para o paciente Que a vivencia, porém uma experiência múltipla para os profissionais de enfermagem, como alude um deles:

“... o Que é rotina para nós, é totalmente novo para o paciente [...". (p7)

Por essa razão, "naturalmente" é como se comporta a maioria dos profissionais nas situações/condições apontados, independentemente do sexo do paciente, pois consideram condições normais/ naturais no cotidiano das atividades de enfermagem, principalmente em ambiente de UTI.

"Atuo de forma natural, pois já estou acostumada com essa situação..." (p2)

“... a enfermagem é uma profissão Que dispensa a diferença sexual. (pI)

“... com o passar do tempo, a rotina dos procedimentos tornase normal". (pl9)

A assistência de enfermagem tem destaque no atendimento de necessidades básicas dos pacientes Que envolvem segurança ${ }^{(8)}$ e confiança no contexto de internação em ambiente de cuidados intensivos ${ }^{(9)}$.

"Não expor o paciente, deixando-o envergonhado. Mostrar que essa é uma técnica normal que é para seu conforto. Essa abordagem é realizada com calma, olhando em seus olhos, passando segurança e bem estar". (p 19)

“... ao mostrar preocupação em não expô-lo, ele (a) sentirá mais confiança em nosso trabalho". (p5)

Asseveram os profissionais deste estudo Que assumem a postura profissional de um agir "natural", buscando transferir ao paciente segurança, confiança, proteção, conforto e bem-estar durante a exposição do seu corpo, respeitando-o eticamente.

\section{Respeitando o outro em sua singularidade e privacidade: um exercício de empatia}

Os profissionais relatam que, antes de realizarem procedimentos Que expõem o corpo ou partes íntimas dos pacientes, comunicam, informam e explicam o cuidado a ser realizado, como e por Que, obtendo para isso o consentimento devido. Todavia, sempre os respeitam em sua decisão no caso de não permissão para o cuidado, sobretudo salientando o estímulo para o autocuidado.

Evidencia-se que os profissionais de enfermagem se preocupam em esclarecer aos pacientes sobre procedimentos Que implicam na exposição corporal na UTI, valorizando suas necessidades de conhecimento e compreensão acerca das intervenções da assistência de enfermagem ${ }^{(10)}$, como revelam as falas:

"Sempre explico o que será feito e, depois de orientado, é que será realizado o cuidado" (p7).
“... perguntar a ele Quando está acordado se aceita receber os cuidados mais íntimos ou se ele (a) mesmo quer realizá-lo, Quando possível". (p2)

Nos depoimentos identificam-se múltiplos cuidados que visam garantir a privacidade dos pacientes, minimizando a exposição física e protegendo sua intimidade, visto Que a inibição e a vergonha são inevitáveis nessas situações. Assim, eles podem se sentir seguros e confiantes com a atuação do profissional de enfermagem, além de minimamente confortáveis, em ambiente reservado.

$\mathrm{O}$ uso de biombos e o fechamento de cortinas laterais visam proporcionar ambiente reservado. A exposição mínima do corpo, descobrindo apenas o necessário ou cobrindo partes Que não precisam ficar expostas com compressas, lençóis e camisolas, resguarda a privacidade do paciente ${ }^{(4,10-1 I)}$, principalmente Quando o fluxo de pessoas é maior na UTI.

“Utilização de biombos, com o mínimo de pessoas no box, principalmente no turno da manhã, onde o fluxo de pessoas é bem maior". ( $\mathrm{p} 5)$

“Procuro descobrir o mínimo do corpo possível”. (p22)

“... sempre que faço higiene corporal... deixa sua intimidade coberta com a camisola". (p20)

Os depoimentos corroboram resultados de outro estudo, o Qual revelou Que os profissionais de enfermagem estão atentos ao resguardo da intimidade dos pacientes, manifestando a preocupação em preservar a sua privacidade, inclusive nos eventos em Que a nudez parcial ou total é inevitável ${ }^{(10)}$.

Constata-se Que os cuidados realizados pelos profissionais seres cuidadores - na assistência ao paciente, preservando a sua privacidade, estão alicerçados na capacidade de empatia, ou seja, as medidas de proteção adotadas pela equipe são determinadas com base no imaginário de Que o paciente poderia ser um familiar ou o próprio profissional na condição de ser cuidado. Assim elucidam os discursos:

"I... I nunca expor o paciente, por mais que ele esteja inconsciente. Devemos nos pôr no lugar deles, ou então imaginar Que fosse um familiar nosso". (p20)

“... Não é uma coisa normal para eles. Somos pessoas estranhas e isso traz inibição e vergonha. Às vezes me coloco no seu lugar, não seria nada tranquilo. Ninguém gosta de se expor". (p 13)

Evidencia-se Que os profissionais de enfermagem entendem a exposição do corpo e da intimidade como condição de constrangimento $^{(1 \mathrm{II})}$ para os pacientes, como elucidam os depoimentos:

"A exposição corporal é algo difícil e constrangedor para todos os pacientes. Alguns tentam controlar esse sentimento; alguns tentam se cobrir de alguma forma, alguns falam ou fazem brincadeiras para amenizar a situação". (p4)

Algumas afirmações: 
“... temos que ter consciência que ali poderia estar o nosso familiar, e são pessoas extremamente reservadas". (p5)

\section{“... mesmo com pacientes sedados ou em coma tentando sempre fazer empatia". (p3)}

Dessa forma, Quando o ser cuidador se projeta para o lugar do ser cuidado, toma consciência de si mesmo, ou seja, é em razão da sua capacidade de se colocar no lugar do outro Que os profissionais são capazes de avaliar e escolher Que cuidado dispensar ${ }^{(12)}$.

\section{A intimidade: dificuldades vividas pelos profissionais e reações dos pacientes}

\section{Dificuldades humanas}

As dificuldades manifestadas pelos profissionais de enfermagem em lidar com situações Que envolvem a exposição física do paciente ocorreram principalmente durante o processo de formação e no início da atuação profissional ao expor pacientes. Mesmo Que conscientes, orientados e comunicativos, a condição de constrangimento acentuava-se durante a exibição de partes íntimas, em especial do sexo oposto ${ }^{(10)}$. Contudo, atualmente percebida com naturalidade, como assinalado anteriormente.

"No início da vida profissional senti um pouco de dificuldade, Hoje trato com muita naturalidade". ( $\mathrm{pl} 7$ )

“.... na época de estágio achava muito estranho e me sentia envergonhada Quando precisava fazer algum procedimento no sexo masculino". (p6)

Dadas as dificuldades manifestadas pelos profissionais relacionadas à exposição do corpo e da intimidade dos pacientes no período de formação e início da atuação em enfermagem, podese inQuirir se o tema em Questão é abordado nas escolas formadoras considerando as experiências vividas do aluno; se ocorre o estímulo pelos formadores à reflexão consciente e crítica da postura e do agir profissional nas condições Que expõem física e intimamente os pacientes, com vistas a garantir ao ser cuidador e ao ser cuidado uma experiência menos constrangedora.

Para não haver constrangimento para ambos (pacientes e profissionais) em cuidados Que reQuerem a exposição física e íntima, os participantes apontam a necessidade do diálogo; do agir de forma natural e da utilização de recursos de proteção para assegurar privacidade e segurança ao paciente. Tais cuidados de enfermagem sinalizam o respeito pelo outro, visto Que o diálogo/comunicação possibilitam ao paciente a expressão de seus sentimentos e medos, devendo os profissionais de enfermagem valorizarem as Queixas e proporcionar esclarecimentos $^{(1,3)}$.

\section{Dificuldades estruturais}

Admitem os profissionais Que a estrutura física da UTI estudada dificulta a preservação da privacidade do paciente, embora sinalizem o valor dessa atitude ${ }^{(1)}$. Assim, sugerem para melhoria desta condição a alocação dos pacientes por sexo, em box distintos, separados por cortinas ou outros para maximizar as suas condições de privacidade.
"O ideal seria que os pacientes fossem distribuídos em box individuais, já que fica difícil de dispor de tantos biombos..." (pl)

“... Deveria ser separado os pacientes masculinos num box e feminino no outro. Mas não dá, a UTI está sempre lotada". (p2I)

Pelo fato de a UTI possuir elevada taxa de ocupação, a separação por sexo, na iminência de gravidade, é considerada importante, embora de difícil operacionalização.

\section{Reações dos pacientes tendo seu corpo exposto: uma visão dos profissionais}

Tendo o próprio corpo exposto, total ou parcialmente, são inevitáveis as reações dos pacientes, as Quais são, na percepção dos profissionais de enfermagem: constrangimento, vergonha, medo, ansiedade, tristeza, preocupação, insegurança, fragilidade, desconforto, invasão, entre outros. Tais reações são evidenciadas principalmente nos idosos, Quando atendidos pelo sexo oposto. Assim, com frequência eles solicitam que o cuidado seja realizado por profissional do sexo deles. Comumente isso é manifestado pelas mulheres, as Quais são beneficiadas já Que o gênero feminino ainda é predominante na profissão. Em oposição, os pacientes do sexo masculino, Que nem sempre podem ser cuidados por profissional do mesmo sexo, em razão do pouco número destes nas instituições hospitalares.

Destaca-se, dessa forma, a relevância em viabilizar a inserção de mais trabalhadores do sexo masculino na equipe de enfermagem, o Que proporcionaria o cuidado aos pacientes homens por profissionais do mesmo sexo ${ }^{(10)}$.

Descrevem os profissionais Que os pacientes, mesmo Quando conscientes, "poucos expressam isso (seus sentimentos) em palavras" (p 12), e "ficam calados, pouco comunicativos e só Questionam se vai demorar ainda” (p l 3), no entanto demonstram sua ineuietação e, diante da condição de impotência, revelam:

“... não sirvo nem mesmo para me higienizar" ou “... eu não sou nada mesmo". (p3)

"a que ponto chega uma pessoa para estar passando por tudo aquilo e depender dos outros para tudo". ( p I7)

Os profissionais inferem ser constrangedor para os pacientes até comentar sobre o assunto. Em algumas situações, alguns se negam a receber cuidados Que os exponham; então, havendo explicação/orientação/diálogo sobre a necessidade, ocorre aceitação ${ }^{(1)}$, porém requerem Que parte do corpo, pelo menos, esteja coberta durante o procedimento.

Quando se trata de higiene corporal, o paciente consciente, tendo condições de autocuidado, auxilia na própria higiene. Todavia, os Que não conseguem executar o autocuidado, mesmo constrangidos com a exposição, agradecem o cuidado recebido.

Sobre as reações dos pacientes conscientes e comunicativos do sexo masculino, uma profissional manifesta dificuldade ao se deparar com "situações desagradáveis, em certas atitudes de pacientes "engraçadinhos..." (p2). Sobretudo, é também dificuldade 
vivida pela equipe de enfermagem realizar cuidados íntimos com exposição física Quando o paciente demonstra estar constrangido. Em contrapartida, outros sujeitos assinalam:

"Minha maior dificuldade se encontra em conversar com o paciente comatoso ou sob efeito de sedativos, sendo que muitos reagem. Acabo abandonando-o, sem antes explicar-lhe o motivo de minha ação". (pl)

“... no caso de pacientes conscientes, o constrangimento em relação a procedimentos é grande; já no caso inconsciente não". (p5)

Cientes de Que os pacientes, mesmo com o nível de consciência diminuído, têm condições de percepção, os profissionais ressaltam Que os cuidados deveriam ser igualitários, tanto para o Que está consciente Quanto para o Que tem comprometido o seu estado neurológico. No entanto, na prática ocorrem contradições Quanto ao Que é falado e o Que é vivido, como analisado na próxima categoria.

\section{Desproteção da intimidade do paciente: contradições Que emergem da prática}

Entende-se que manter a privacidade do paciente em UTI é uma tarefa difícil, em razão da estrutura física e do tipo de cuidado. Embora os profissionais de enfermagem sinalizem preocupação, evidenciam-se situações e condições de des-cuidado Quanto à proteção corporal| $^{(11)}$.

“[...] muitas vezes ou Quase sempre acabo deixando de lado esse cuidado". (p2)

“Explico para o paciente o que vou fazer e por que, mas já esQueci várias vezes de fazer isso [proteger o corpo e a intimidade do paciente]". (p6)

O cuidado e a preocupação em preservar a privacidade dos pacientes, em especial jovens, revelam-se Quando estão conscientes, o Que não ocorre Quando em estado de sedação, torpor ou coma. Nestes casos, a exposição íntima acontece durante o banho.

"Quando o paciente está acordado sim, mas sinceramente, Quando sedados, acabamos deixando a desejar em relação a este cuidado". (p2)

"Quando cuido de pacientes acordados sim, são usados biombos, se expõe ao mínimo o paciente; Quando são clientes sedados, em coma ou mesmo torporosos, nem sempre são utilizados esses meios. Acredito que a abordagem deveria ser igual para todos". (p3)

“A preocupação existe, porém não é tão cuidadosa devido às características físicas do setor e, talvez, a sua própria rotina, mas principalmente pelo fato de que a maioria dos pacientes são comatosos ou estão sedados". (pl)

Os profissionais de enfermagem confirmam nos depoimentos a persistência de falhas referentes à proteção do corpo e da intimidade dos pacientes, reconhecendo Que a privacidade é violada constantemente durante a assistência ${ }^{(4)}$, sem explicação ou consentimento, configurando invasão pessoal, Que desrespeita e banaliza o outro $^{(13-14)}$. Dessa forma, emerge a necessidade do pensar/ refletir sobre tais condutas, Que impelem mudanças na realidade apresentada, como apontam os próprios profissionais:

“A gente só pensa mais Quando discute sobre isso... Todo mundo faz as coisas sem maldade e o corpo fica à mostra, principalmente no banho. Se o paciente está acordado (não sedado), tenho alguma preocupação, mas normalmente não protejo o paciente; poucas vezes coloco o biombo.... Acho que precisaria mudar, pois, se a gente tivesse no lugar do paciente, gostaria Que fosse diferente". (p21)

“... pelo Que vejo e sei, na hora do banho tem pouca gente na UTI e não protegemos os pacientes. Mas essa pergunta me fez pensar.. Seria bom tomar mais cuidado com a exposição do paciente". (p22)

Proporcionar momentos dialógicos sobre o tema na esfera do cuidado à saúde faz-se pertinente, na medida em Que se devem considerar as múltiplas dimensões do ser humano, respeitando-o em sua unidade e multiplicidade, ou seja, em sua cultura, crenças, sexo, ambiente e fé(15).

Urge entender os motivos Que levam as ações de violação da privacidade e autonomia dos pacientes, denotando falha ou descuido por parte de alguns profissionais, o Que pode representar para os pacientes desrespeito e desconsideração por parte da equipe, bem como impessoalidade e desumanização no atendimento ${ }^{(10)}$.

É oportuno, aQui, citar o Código de Ética de Enfermagem ${ }^{(16)}$, o Qual exige o respeito ao pudor, à privacidade e intimidade do cliente. Contudo, são os valores e os princípios de cada cuidador Que favorecem sua percepção das coisas e norteiam o cuidado, balizando suas ações e atitudes ${ }^{(1)}$. Assim, munidos dos preceitos éticos da profissão e da moral, os profissionais atribuem valor ao tema em Questão. Portanto, os Que violam a privacidade do outro devem refletir sobre sua prática e sua relação com o paciente, de modo a prover a este outro um cuidado ético e responsável.

\section{CONSIDERAÇÕES FINAIS}

O estudo revela que a exposição do corpo e da intimidade é uma condição única para o paciente e uma experiência múltipla para os profissionais de enfermagem. Com base nessa premissa, a maioria dos profissionais manifesta agir naturalmente, tendo preocupação e empatia para como o paciente; por isso, utilizam recursos materiais e humanos para proporcionar um ambiente reservado e exposição mínima do corpo do paciente (Quando necessária), como o biombo. Ainda assim, condutas Que violam a privacidade ainda persistem durante o cuidado de enfermagem na UTI.

De acordo com as dificuldades expressas pelos participantes, percebe-se a necessidade de abordar ainda na formação e no início da prática profissional as Questões Que envolvem a exposição física e íntima do paciente e de proporcionar melhorias estruturais às unidades de pacientes críticos, o Que requer investimentos 
financeiros.

Ainda, mostra-se relevante a reflexão da equipe de enfermagem sobre o imperativo moral do cuidado Quanto à privacidade e dignidade do paciente no ambiente de UTI, visto Que a rotina do trabalho pode inibir a percepção de alguns profissionais. $O$ conhecimento das reações dos pacientes manifestadas durante a exposição física e íntima poderá subsidiar as atitudes destes profissionais, visando minimizá-las e abrandá-las.
Com este estudo, realizado a partir das experiências vividas pelos profissionais de enfermagem que atuam em UTI, foi possível compreender Questões relacionadas à privacidade do paciente e suas implicações. A privacidade é um direito do paciente e um compromisso ético do profissional. Sobretudo, foi possível instigar a reflexão dos participantes - profissionais de enfermagem - sobre o tema, suscitando, mesmo Que timidamente, possibilidades de mudanças no contexto de atuação.

\section{REFERÊNCIAS}

1. Nascimento ERP, Trentini M. O cuidado de enfermagem na unidade de terapia intensiva: teoria humanística de Paterson e Zderad. Rev Latino-am Enfermagem 2004; 12(2): 250-7.

2. Fabriz DC. Bioética e direitos fundamentais: a bioconstituição como paradigma ao biodireito. Belo Horizonte: Mandamentos; 2003.

3. Silveira MF. A. Estar despido na unidade de terapia intensiva: duas percepções, um encontro. Rev Enferm UERJ 1997; 5(2): 449-59.

4. Pupulim ISL, Sawada NO. O cuidado de enfermagem e a invasão da privacidade do doente: um Questão ético-moral. Rev Latinoam Enfermagem 2002; 10(3): 433-8.

5. Ministério da Saúde (BR). Pesquisa com seres humanos. Resolução 196/96. Brasília: Ministério da Saúde; 1996.

6. Minayo MCS. Desafio do conhecimento. São Paulo: HucitecAbrasco; 2000.

7. Minayo MCS. Pesquisa social. Petrópolis: Editora Vozes; 2002.

8. Cantillo EV. Seguridad de los pacientes. Un compromiso de todos para un cuidado de calidad. Salud Uninorte 2007; 23(I): 112-9.

9. Lemos RCA, Rossi LA. O significado cultural atribuído ao centro de terapia intensiva por clientes e seus familiares: um elo entre a beira do abismo e a liberdade. Rev Latino-am Enfermagem
2002; I0(3): 345-57.

10. Pupulim ISL, Sawada NO. Exposição corporal do cliente no atendimento das necessidades básicas em UTI: incidentes críticos relatados por enfermeiras. Rev Latino-am Enfermagem 2005; 13(3): 388-96.

I I. Pupulim ISL, Sawada NO. Exposição corporal do cliente durante a avaliação física em Unidade de Terapia Intensiva. Rev Bras Enferm 2005; 58(5): 580-5.

12. Vila VSC, Rossi LA. O significado cultural do cuidado humanizado em unidade de terapia intensiva: muito falado e pouco vivido. Rev Latino-am Enfermagem 2002; 10(2): 137-44.

13. Prochet TC, Silva MIP. Proxêmica: as situações reconhecidas pelo idoso hospitalizado que caracterizam sua invasão do espaço pessoal e territorial. Texto Contexto Enferm 2008; 17(2): 32 I-6.

14. Prochet TC, Silva MJP. Situações de desconforto vivenciadas pelo idoso hospitalizado com a invasão do espaço pessoal e territorial. Esc Anna Nery Rev Enferm 2008; 12 (2): 3 I0-5.

15. Morin E. Introdução ao pensamento complexo. Porto Alegre: Sulina; 2006.

16. Conselho Federal de Enfermagem (BR). Código de ética dos profissionais de enfermagem [internet]. Rio de Janeiro; 2007 [citado em: 2009 lan 16]. Disponível em: http://www.portalcofen.gov.br/ 2007/materias.asp?ArticleID $=7323 \&$ sectionID $=37$. 